\title{
Regional variation in post-stroke multidisciplinary rehabilitation care among veteran residents in community nursing homes
}

This article was published in the following Dove Press journal:

Journal of Multidisciplinary Healthcare

I March 2017

Number of times this article has been viewed

\author{
Huanguang Jia' \\ Qinglin Pei' \\ Charles T Sullivan' \\ Diane C Cowper Ripley' \\ Samuel SWu' \\ W Bruce Vogel' \\ Xinping Wang' \\ Douglas E Bidelspach² \\ Jennifer L Hale-Gallardo' \\ Barbara E Bates ${ }^{3}$ \\ 'Center of Innovation on Disability \\ and Rehabilitation Research, North \\ Florida/South Georgia Veterans Health \\ System, Gainesville, FL, ${ }^{2}$ Physical \\ Medicine and Rehabilitation Service, \\ Department of Veterans Affairs, \\ Washington, DC, ${ }^{3}$ Aleda E. Lutz VA \\ Medical Center, Saginaw, MI, USA
}

\begin{abstract}
Introduction: Effective post-acute multidisciplinary rehabilitation therapy improves stroke survivors' functional recovery and daily living activities. The US Department of Veterans Affairs (VA) places veterans needing post-acute institutional care in private community nursing homes (CNHs). These placements are made under the same rules and regulations across the VA health care system and through individual per diem contracts between local VA facilities and CNHs. However, there is limited information about utilization of these veterans' health services as well as the geographic variation of the service utilization.
\end{abstract}

Aim: The aims of this study were to determine rehabilitation therapy and restorative nursing care utilization by veterans with stroke in VA-contracted CNHs and to assess risk-adjusted regional variations in the utilization of rehabilitation therapy and restorative nursing care.

Methods: This retrospective study included all veterans diagnosed with stroke residing in VAcontracted CNHs between 2006 and 2009. Minimum Dataset (a health status assessment tool for $\mathrm{CNH}$ residents) for the study CNHs was linked with veterans' inpatient and outpatient data within the VA health care system. CNHs were grouped into five VA-defined geographic regions: the North Atlantic, Southeast, Midwest, Continental, and Pacific regions. A two-part model was applied estimating risk-adjusted utilization probability and average weekly utilization days. Two dependent variables were rehabilitation therapy and restorative nursing care utilization by veterans during their $\mathrm{CNH}$ stays.

Results: The study comprised 6,206 veterans at 2,511 CNHs. Rates for utilization of rehabilitation therapy and restorative nursing care were $75.7 \%$ and $30.1 \%$, respectively. Veterans in North Atlantic and Southeast CNHs were significantly $(p<0.001)$ more likely to receive rehabilitation therapies than veterans from other regions. However, veterans in Southeast CNHs were significantly $(p<0.001)$ less likely to receive restorative nursing care compared with veterans in all other regions, before and after risk adjustment.

Conclusion: The majority of veterans with stroke received rehabilitation therapy, and about onethird had restorative nursing care during their stay at VA-contracted CNHs. Significant regional variations in weekly days for rehabilitation therapy and restorative nursing care utilization were observed even after adjusting for potential risk factors.

Keywords: nursing home, rehabilitation, restorative care, stroke, utilization

\section{Introduction}

Rehabilitation therapy includes various treatments (eg, physical therapy, occupational therapy, speech pathology) aimed to increase patient functional independence, prevent further loss of function, and improve quality of life for individuals with disabilities. Restorative nursing care is a program available in nursing homes that helps maintain patient progress made during rehabilitation therapy and enhances functional capacity.

Tel +l 352376 I6I l ext4926

Fax +I 352 27I 4540

Email Huanguang.jia@va.gov 
According to the US Department of Veterans Affairs/Department of Defense (VA/DoD) clinical practice guideline for the management of adult stroke rehabilitation care, effective multidisciplinary rehabilitation therapy and restorative nursing care improve stroke survivors' functional recovery. ${ }^{1}$ In addition to its 134 Community Living Centers (CLCs), the VA also places veteran enrollees needing post-acute institutional care in private community nursing homes $(\mathrm{CNHs})$ under a per diem contractual program. Nursing home contracts outside the VA health care system meet veterans' increasing needs in post-acute institutional care and were implemented in response to the Millennium Act of 1999 requirement. $^{2}$ Under the per diem contract program, veteran $\mathrm{CNH}$ placement is decided based upon several conditions such as VA CLC bed availability, patient long-term care needs defined by patient hospital discharge assessment, patient priority for VA health care (eg, service connected status, level of disability, and income), and patient preferences (eg, proximity to veterans' home or family). ${ }^{3}$ Veterans' length of stay (LOS) and rehabilitation therapy needs at the $\mathrm{CNH}$ are defined in the individual contract between local VA facility and CNHs. However, the contract may be renewed and the veteran's LOS may be extended if needed. VA Handbook 1143.2, VA Community Nursing Home Oversight Procedures, outlines the per diem program and specific requirements for a $\mathrm{CNH}$ qualifying for a contract. ${ }^{4}$

Each year, VA contracts with $>2,500 \mathrm{CNHs}$, and these contracts are usually initiated at local VA medical centers. ${ }^{4,5}$ The US General Accountability Office criticized the CNH per diem program in their report dated 2001 and 2004 for lacking a system-wide quality monitoring and oversight mechanism and lacking national data to track health services and care quality for veteran residents. ${ }^{4,6}$

In an early study, Johnson et al reported that VA-contracted CNHs differed from their counterparts without a VA contract; they were more likely to be larger and for-profit and less likely to be hospital-based and to meet Centers for Medicare and Medicaid Services (CMS) recommended minimum certified nursing assistant and registered nurses staffing. Additionally, the VA-contracted CNHs had more residents enterally tube fed, newly catheterized, mobility restrained, and who had developed new pressure ulcers. ${ }^{\text {? }}$

In a recent study comparing post-stroke rehabilitation and restorative care utilization by veterans in CLCs and CNHs, we found that before and after risk adjustment, $\mathrm{CNH}$ veterans had significantly more average rehabilitation therapy days, but CLC veterans had significantly more average days for restorative nursing care. ${ }^{8}$ In that study, we were limited by imperfect matching of available data for CNHs and CLCs.
For example, the resident/nurse ratio and facility quality deficiency scores were not available for CLCs. ${ }^{7}$ Furthermore, we excluded 594 CLC-CNH dual users in our analysis to enhance the comparability between the two types of facilities. The earlier limitations motivated further assessment of the rehabilitation therapy and restorative nursing care received by veterans with stroke at $\mathrm{CNHs}$ with VA contract.

The objectives of this retrospective observational study were, 1) to determine rehabilitation therapy and restorative nursing care utilization by veterans with stroke in VA-contracted CNHs, and 2) to assess risk-adjusted regional variations in the utilization of rehabilitation therapy and restorative nursing care. Such information is important as post-acute rehabilitation enhances stroke survivors' functional recovery and daily living activities. ${ }^{9-11} \mathrm{CNHs}$ are major non-VA health care recovery resources for veterans with stroke, and yet our understanding of this topic is limited. Our research questions were as follows: How many veterans with stroke have received rehabilitation therapy and restorative nursing care during their stay at the $\mathrm{CNHs}$ ? Are there any geographic variations in the utilization of rehabilitation therapy and restorative nursing care across the five VA regions? We hypothesized that there are no significant regional variations in the utilization of rehabilitation therapy and restorative nursing care after adjusting for the potential risk factors.

\section{Methods \\ Study design}

This is a retrospective study using existing relevant VA and CNH data.

\section{Study sample}

The study sample included all veterans diagnosed with stroke and admitted to CNHs with a VA contract from January 1, 2006, through December 31, 2009. In the Minimum Dataset (MDS) used for the study, the variable, "IIT_STROKE", indicates the primary medical diagnosis of the veteran residents at the time of their admission to the CNHs. This variable was used for the stroke diagnosis of the study sample. All eligible veterans were followed up for a maximum of 12 months postadmission date. This study was approved by the Institutional Review Board (IRB) at the University of Florida and the Research and Development Committee (R\&DC) at the North Florida/South Georgia Veterans Health System, Gainesville, FL, USA. This study was of minimal risk with a retrospective design and used existing administrative data from multiple data sources. As such, the study was reviewed and approved by our IRB and R\&DC as an expedited protocol with a waiver of informed consent. 


\section{Research data}

Research data were from three major databases. First, the CMS MDS (MDS 2.0) provided the veterans' baseline sociodemographics and service utilization at the CNHs. The MDS is a standardized clinical assessment tool of health status of all residents in Medicare- and/or Medicaid-certified nursing homes. The MDS contains items on residents' health care utilization and functional capabilities, and it helps nursing home staff identify residents' health problems. ${ }^{12}$ Rehabilitation therapy and restorative nursing care utilization data were collected as a part of the MDS assessment information. All VA-contracted facilities were CMS Medicare or Medicaid certified. US Federal government mandates these facilities to conduct an assessment for all residents at admission, after a significant change in health status, quarterly, annually, and at discharge, regardless of payment source. ${ }^{13}$ Second, we used VA national inpatient and outpatient data files obtaining the veterans' relevant VA inpatient/outpatient clinical information 12 months prior to their nursing home admission. ${ }^{14}$ Finally, the VA National Fee Basis inpatient and outpatient treatment files provided veterans' relevant sociodemographic and clinical information on covered care provided outside of VA facilities.

We used a unique patient identifier (scrambled Social Security Number [SSN]) linking the multiple-source data as follows: 1) to identify eligible veterans in the 2006-2009 CMS MDS data and create two identifier files (scrambled SSN for veterans and facility identifier file for the CNHs); 2) to apply the veteran identifier in the VA and Fee Basis inpatient and patient data sets obtaining and confirming the sociodemographic and clinical information; and 3) to match the facilities in the Medicare Nursing Home Compare file to obtain facility characteristics.

\section{Dependent variables}

Dependent variables consisted of weekly days for rehabilitation therapy and restorative nursing care. The MDS recorded the number of days for each specific type of the rehabilitation therapy and restorative nursing care provided to a resident for $\geq 15$ minutes per day in the last 7 days prior to an assessment date.

For rehabilitation therapy, we first calculated the average number of days for each type of rehabilitation therapy (i.e., physical, occupational, speech, and/or respiratory therapy), then we derived a total score summing across all types of rehabilitation therapies by geographic region.

Similarly, we applied the steps mentioned earlier, obtaining the regional totals and average days for restorative nursing care (i.e., active range of motion, walking, passive range of motion, bed transfer, dressing and/or grooming, eating and/ or swallowing, bed mobility, and communication). These restorative techniques denoted the nursing interventions in assisting, promoting, or maximizing a resident's ability, independent living, and functional potential.

\section{Independent variable}

Independent variable is the MyVA regions. MyVA regions include five geographic regions: the North Atlantic, Southeast, Midwest, Continental, and Pacific regions. A map of the districts can be found at http://www.blogs.va.gov/VAntage/16786/ ${ }^{15}$ The regional assignment was based on CNH's state location. If multiple facilities were used by a veteran during the follow-up time period, we chose the facility with the longest days of stay and the most post-admission assessments.

\section{Facility characteristics}

The facility characteristics are as follows: 1) rural/urban facility was designated by linking CNH ZIP codes with the ZIP codes in the VA rural/urban definition. With this VA definition, urban refers to population density $\geq 1,000$ civilians per square mile and rural refers to any non-urban rural or highly rural area. ${ }^{16,17}$ 2) Beds number was the number of facility Medicare-certified beds during the study time frame.

3) Resident/nurse ratio was the number of residents divided by the total number of full-time registered nurses per facility.

4) Resident/bed ratio was the number of residents divided by the total number of facility-certified beds. 5) Ownership referred to non-profit, for-profit, or local government owned. 6) Hospital-based status indicated whether a facility was affiliated with a hospital during the study. 7) Weighted Deficiency Sum Score (numerical): Scope and Severity is a national system used by all-state survey agencies to rate $\mathrm{CNH}$ deficiencies. To be certified for Medicare and Medicaid programs, all CNHs are required to have scope and severity surveys annually. The score from the survey indicates a CNH's deficiency severity. The weighted deficiency sum score was calculated by multiplying CMS deficiency weights by the number of scope and severity identified for each facility. The weighted sum score indicated that a facility's deficiency rating did not meet the federal regulatory requirements for the standard quality of care: the higher the score, the worse the quality of care. ${ }^{18}$

\section{Veteran characteristics}

The veteran characteristics are as follows: 1) age was veteran's age at nursing home admission using the formula: age $=($ admission date - date of birth $) / 365.25$ days. This variable was divided into five ranges (i.e., $\leq 64,65-69,70-74,75-79$, and $\geq 80$ years). This categorical age variable allows us to 
make a distinction between different age groups and the utilization outcomes. For example, veterans 65 years and older are more likely to be dually eligible for VA and Medicare health care programs, and dually eligible veterans are likely to receive more services than those veterans who only have VA health care coverage. 2) Gender (male, female) was a dichotomous variable. 3) Education was divided into five categories: $<$ high school, high school, some college, bachelor degree, and graduate degree. 4) Race/ethnicity was categorized into three groups (White, African-American, and all others). 5) Marital status was coded as never married, married, widowed, or separated/divorced. 6) VA health care priority was derived from two variables existing in the VA inpatient databases: "percent service-connected", a number between 0 and 100 , is determined based on the major diagnosis responsible for the hospital stay, and "means test indicator" is used to determine veteran eligibility to receive care within the VA health care system in addition to the percent service-connected. For this study, VA health care priority was coded as high if veterans' percent service-connected and means test category indicated that they were all compensable service-connected ( $\geq 10 \%$ ) or non-service-connected (eg, prisoner of war, World War I, and low-income veterans). All others were coded as low. ${ }^{19,20}$ 7) Admission source indicated veteran's location before nursing home admission. We coded this variable as acute care hospital, non-acute hospital, nursing home, and all others. 8) Baseline activities of daily living (ADL) score was composed of the seven MDS functional measures sum (i.e., bed mobility, transfer, locomotion, dressing, eating, toilet use, and personal hygiene) at admission. In the MDS 2.0 , each measure was entered as a value of 0 through 4 , with 0 representing independent status and 4 representing a totally dependent status. The ADL functioning total score at baseline or admission ranged from 0 to 28 , with lower values representing higher functional status. ${ }^{21,22}$ 9) Comorbidity was measured using the modified Charlson's comorbidity index by D'Hoore et al. ${ }^{23}$ The index assigned weights for major comorbid diseases. The total assigned weights represented a measure of comorbid disease burden: the higher the score, the more severe the comorbid disease burden. We removed stroke diagnosis from the index since all veteran residents were stroke patients. The VA national inpatient and outpatient files and VA Fee Basis inpatient and outpatient files were used to obtain the diagnoses for the comorbid sum score calculation.

\section{Statistical analysis}

SAS version 9.4 (SAS Institute, Cary, NC, USA) was used for all data analyses. First, descriptive statistics were obtained on all the variables. Statistical inference (chi-squared test or
Fisher's exact test on discrete variables and analysis of variance [ANOVA] test on continuous variables) was performed to compare the facility and veteran characteristics and utilization between the five regions. Second, a two-part regression model with backward elimination method was fitted, 1) to estimate the risk-adjusted probability of receiving rehabilitation therapy and restorative care using logistic regression, and 2) to evaluate the risk-adjusted expected weekly days for the utilization among the users based on general linear regression. The correlation coefficient was examined to test the potential harmful multicollinearity among all covariates. Consequently, we removed the patient rural/urban resident variable from our final models due to high collinearity with facility rural/urban characteristics.

\section{Results}

This study comprised 6,206 veterans diagnosed with stroke at 2,511 VA-contracted CNHs between 2006 and 2009.

Table 1 shows the facility characteristics and regional comparisons. North Atlantic region facilities were significantly different from other regions in many ways: larger in average certified beds, higher in resident/beds ratio, lower in resident/full-time nurse ratio, and more likely to be non-profit homes and run by local governments with lower weighted deficiency sum score. Continental region facilities were more likely to be in rural areas and have higher resident/full-time nurse ratio, but their resident/bed ratio was lower than other regions. Pacific region facilities were more likely to be hospital-based, for-profit, and in urban areas. Continental and Pacific region facilities had the worst deficiency score, although Continental region facilities have twice as many residents per nurse as Pacific region facilities.

Table 1 presents regional comparisons of veteran characteristics. North Atlantic CNH veterans were significantly older with lower education level and more likely to be married. Southeast CNH veterans were more likely to be AfricanAmerican and admitted from acute care hospital with high VA health care priority. Midwest $\mathrm{CNH}$ veterans were more likely to be younger, White, and single with lower average ADL score at baseline. Pacific $\mathrm{CNH}$ veterans were more likely to be non-White and non-African-American with higher education level and a heavier burden of comorbid conditions.

Table 2 provides the regional comparisons of veterans' average weekly days for rehabilitation therapy and restorative nursing care during their CNH stays. Among the 6,206 veterans, the proportion of rehabilitation therapy and restorative nursing care users was $75.7 \%$ and $30.1 \%$, respectively, and the observed weekly rehabilitation therapy and restorative nursing care utilization averaged $6.4 \pm 4.4$ and $5.9 \pm 6.2$ days, 
Table I Comparison of facility and resident characteristics by region

\begin{tabular}{|c|c|c|c|c|c|c|c|}
\hline Variables & All & North Atlantic & Southeast & Midwest & Continental & Pacific & $p$-value ${ }^{\dagger}$ \\
\hline \multicolumn{8}{|l|}{ Facility } \\
\hline Number of residents & 6,206 & I,622 (26.1) & $1,209(19.5)$ & I,I09 (17.9) & $1,009(16.3)$ & $1,258(20.0)$ & \\
\hline Number of facilities & 2,511 & $590(23.1)$ & $476(19.0)$ & $595(23.7)$ & $433(17.2)$ & $427(17.0)$ & \\
\hline Resident/facility range & $1-119$ & $1-119$ & $1-40$ & $1-79$ & $1-30$ & $1-65$ & \\
\hline Rural facility & $2,768(44.6)$ & $651(40.1)$ & $440(36.4)$ & $642(57.9)$ & $585(58.0)$ & $450(35.8)$ & $<0.000$ I \\
\hline Certified beds & $|57.73 \pm 98.9|$ & $183.32 \pm 100.29$ & $|43.89 \pm 52.9|$ & $172.62 \pm 158.66$ & $127.40 \pm 45.79$ & $149.23 \pm 82.15$ & $<0.0001$ \\
\hline Resident/nurse ratio & $33.00 \pm 50.61$ & $25.00 \pm 30.09$ & $40.21 \pm 42.65$ & $29.45 \pm 27.10$ & $52.15 \pm 82.04$ & $25.75 \pm 59.30$ & $<0.0001$ \\
\hline Resident/bed ratio & $0.87 \pm 0.14$ & $0.92 \pm 0.08$ & $0.89 \pm 0.11$ & $0.85 \pm 0.14$ & $0.79 \pm 0.18$ & $0.87 \pm 0.15$ & $<0.0001$ \\
\hline Ownership & & & & & & & $<0.0001$ \\
\hline For-profit & $4,025(64.9)$ & $855(52.7)$ & $829(68.6)$ & $717(64.7)$ & $710(70.4)$ & 914 (72.7) & \\
\hline Local government & $1,265(20.4)$ & $404(24.9)$ & $168(13.9)$ & $202(18.2)$ & $211(20.9)$ & $280(22.3)$ & \\
\hline Non-profit & $916(14.8)$ & $363(22.4)$ & $212(17.5)$ & $189(17.1)$ & $88(8.7)$ & $64(5.1)$ & \\
\hline Hospital based $=$ yes & $187(3.0)$ & $25(1.5)$ & $22(1.8)$ & $29(2.6)$ & $25(2.5)$ & $86(6.8)$ & $<0.0001$ \\
\hline Deficiency sum score & $50.8 \pm 69.7$ & $44.9 \pm 53.6$ & $50.2 \pm 82.4$ & $45.3 \pm 54.7$ & $56.8 \pm 84.7$ & $58.7 \pm 72.3$ & $<0.000$ I \\
\hline \multicolumn{8}{|l|}{ Resident } \\
\hline Age, years & & & & & & & $<0.000$ I \\
\hline$\leq 64$ & $\mathrm{I}, 448(23.3)$ & $256(15.8)$ & $342(28.3)$ & $332(30.0)$ & $244(24.2)$ & $274(21.8)$ & \\
\hline $65-69$ & 447 (7.2) & $87(5.4)$ & $101(8.4)$ & $82(7.4)$ & $75(7.4)$ & $102(8.1)$ & \\
\hline $70-74$ & $620(10.0)$ & $165(10.2)$ & $137(\mid 1.3)$ & $103(9.3)$ & $90(8.9)$ & $125(9.9)$ & \\
\hline $75-79$ & $1,006(16.2)$ & $276(17.0)$ & $189(15.6)$ & $160(14.4)$ & $185(18.3)$ & $196(15.6)$ & \\
\hline$\geq 80$ & $2,685(43.3)$ & $838(5 \mid .7)$ & $440(36.4)$ & 431 (38.9) & $4 \mid 5(4 I . I)$ & $561(44.6)$ & \\
\hline Female & $228(3.7)$ & $50(3.1)$ & $49(4.1)$ & $27(2.4)$ & $43(4.3)$ & $59(4.7)$ & 0.0211 \\
\hline Education & & & & & & & $<0.0001$ \\
\hline$<$ High school & $\mathrm{I}, 276(20.8)$ & $383(23.6)$ & $27 \mid(22.4)$ & $252(22.7)$ & $212(21.0)$ & $158(12.6)$ & \\
\hline High school & $2,710(44.2)$ & $736(45.4)$ & $527(43.6)$ & $515(46.5)$ & $412(40.8)$ & $520(4 I .3)$ & \\
\hline Some college & $\mathrm{I}, 400(22.8)$ & $279(17.2)$ & $278(23.0)$ & $227(20.5)$ & $24 \mid(23.9)$ & $375(29.8)$ & \\
\hline Bachelor degree & $493(8.0)$ & $143(8.8)$ & $83(6.9)$ & $65(5.9)$ & $76(7.5)$ & $126(10.0)$ & \\
\hline Graduate degree & $255(4.2)$ & $61(3.8)$ & $43(3.6)$ & $42(3.8)$ & $42(4.2)$ & $67(5.3)$ & \\
\hline Race/ethnicity & & & & & & & $<0.0001$ \\
\hline White & $4,878(78.6)$ & I,342 (82.7) & $855(70.7)$ & $932(84.1)$ & $762(75.5)$ & 987 (78.5) & \\
\hline African-American & $\mathrm{I}, 057(17.0)$ & $255(15.7)$ & $342(28.3)$ & $157(14.2)$ & $158(15.7)$ & 145 (II.5) & \\
\hline All others & $270(4.4)$ & $25(1.5)$ & $12(1.0)$ & $19(1.7)$ & $89(8.8)$ & $125(9.9)$ & \\
\hline Marital status & & & & & & & $<0.0001$ \\
\hline Never married & $767(12.4)$ & $201(12.4)$ & $143(\mid 1.8)$ & $166(15.0)$ & $89(8.8)$ & $168(13.4)$ & \\
\hline Married & $\mathrm{I}, 374(22.1)$ & 437 (26.9) & $250(20.7)$ & $207(18.7)$ & $217(21.5)$ & $263(20.9)$ & \\
\hline Widowed & $\mathrm{I}, 253(20.2)$ & $248(15.3)$ & $253(20.9)$ & $248(22.4)$ & $209(20.7)$ & $295(23.4)$ & \\
\hline Separated/divorced & $2,810(45.3)$ & $736(45.4)$ & $562(46.5)$ & $487(44.0)$ & $493(48.9)$ & $532(42.3)$ & \\
\hline Admission source & & & & & & & $<0.0001$ \\
\hline Acute care hospital & $3,910(63.0)$ & $\mathrm{I}, 067(65.8)$ & $832(68.8)$ & $639(57.7)$ & $547(54.2)$ & $825(65.6)$ & \\
\hline Non-acute hospital & $1,516(24.4)$ & $377(23.2)$ & $237(19.6)$ & $291(26.3)$ & $291(28.8)$ & $320(25.4)$ & \\
\hline Nursing home & $780(12.6)$ & $178(11.0)$ & $140(11.6)$ & $178(16.1)$ & $17 \mid(16.9)$ & $113(9.0)$ & \\
\hline High VA priority & $4,529(74.6)$ & $945(58.3)$ & $977(80.8)$ & $863(77.9)$ & $739(73.2)$ & I,005 (79.9) & $<0.0001$ \\
\hline ADL at baseline & $16.2 \pm 7.3$ & $17.1 \pm 6.6$ & $17.7 \pm 6.6$ & $14.7 \pm 7.6$ & $15.2 \pm 7.9$ & $15.5 \pm 7.4$ & $<0.0001$ \\
\hline Comorbidity & $1.27 \pm 1.56$ & $1.15 \pm 1.37$ & $1.33 \pm 1.69$ & $1.31 \pm 1.64$ & $1.23 \pm 1.50$ & $1.36 \pm 1.64$ & 0.0021 \\
\hline
\end{tabular}

Notes: Data shown as $\mathrm{n}, \mathrm{n}(\%)$, mean \pm SD, or range. ${ }^{\dagger} \mathrm{p}$-values were from multiple comparisons of geographic regions with chi-squared test or Fisher's exact test on discrete variables and ANOVA test on continuous variables.

Abbreviations: SD, standard deviation; VA, Veterans Affairs; ADL, activities of daily living; ANOVA, analysis of variance.

respectively. North Atlantic region had the highest rates of rehabilitation therapy and restorative nursing care, but Southeast region reported more average days in rehabilitation therapy and Midwest region reported more days in restorative nursing care. The most commonly used rehabilitation therapies included physical and occupational therapy, and the commonly used restorative nursing care activities were active range of motion, walking, and passive range of motion.
Part 1 Model results are presented in Table 3. The estimated probability of receiving rehabilitation therapy and restorative nursing care was $76 \%$ and $30 \%$, respectively, with significant regional variations (North Atlantic: 88\%/34\%; Southeast: $83 \% / 23 \%$; Midwest: $66 \% / 28 \%$; Continental: 66\%/30\%; and Pacific: 70\%/34\%) (Table 4).

Significant covariates in the rehabilitation therapy model were rural facility, less certified beds, lower resident/nurse 
Table 2 Regional comparison of weekly therapy/care utilization days ${ }^{\dagger}$ during the 12 months post-admission

\begin{tabular}{|c|c|c|c|c|c|c|c|}
\hline Therapy/care & $\begin{array}{l}\text { All } \\
(N=6,206)\end{array}$ & $\begin{array}{l}\text { North } \\
\text { Atlantic } \\
\text { I,622 (26.I) }\end{array}$ & $\begin{array}{l}\text { Southeast } \\
1,209 \\
(19.5)\end{array}$ & $\begin{array}{l}\text { Midwest } \\
\text { I, } 109 \\
(17.9)\end{array}$ & $\begin{array}{l}\text { Continental } \\
\text { I,009 (16.3) }\end{array}$ & $\begin{array}{l}\text { Pacific } \\
1,258 \\
(20.0)\end{array}$ & $p$-value \\
\hline Rehabilitation therapy & $6.4 \pm 4.4$ & $6.6 \pm 4.4$ & $7.2 \pm 4.4$ & $5.9 \pm 4.4$ & $5.7 \pm 4.2$ & $6.2 \pm 4.3$ & $<0.0001$ \\
\hline Number of users & $4,695(75.7)$ & $\mathrm{I}, 43 \mathrm{I}(88.2)$ & $\mathrm{I}, 005(83.1)$ & 734 (66.2) & $655(64.9)$ & $870(69.2)$ & $<0.000$ I \\
\hline Physical therapy & $2.7 \pm 1.8$ & $2.9 \pm 1.9$ & $3.0 \pm 1.8$ & $2.4 \pm 1.8$ & $2.4 \pm 1.7$ & $2.7 \pm 1.8$ & $<0.000$ I \\
\hline Occupational therapy & $2.5 \pm 1.8$ & $2.6 \pm 1.8$ & $2.7 \pm 1.8$ & $2.3 \pm 1.8$ & $2.2 \pm 1.7$ & $2.4 \pm 1.8$ & $<0.0001$ \\
\hline Speech therapy & $1.0 \pm 1.5$ & $0.9 \pm 1.4$ & $1.3 \pm 1.7$ & $1.0 \pm 1.5$ & $1.0 \pm 1.4$ & $0.9 \pm 1.4$ & $<0.0001$ \\
\hline Respiratory therapy & $0.2 \pm 1.0$ & $0.2 \pm 1.1$ & $0.1 \pm 0.7$ & $0.3 \pm 1.2$ & $0.2 \pm 0.9$ & $0.2 \pm 1.0$ & 0.0039 \\
\hline Restorative nursing care & $5.9 \pm 6.2$ & $6.1 \pm 5.9$ & $5.1 \pm 4.5$ & $7.3 \pm 8.2$ & $5.6 \pm 6.3$ & $5.5 \pm 5.5$ & 0.0001 \\
\hline Number of users & $\mathrm{I}, 867(30.1)$ & $554(34.2)$ & $279(23.1)$ & $310(28.0)$ & $297(29.4)$ & 427 (33.9) & $<0.000$ I \\
\hline Active range of motion & $1.4 \pm 1.8$ & $1.6 \pm 2.1$ & $1.3 \pm 1.7$ & $1.5 \pm 1.9$ & $1.3 \pm 1.6$ & $1.3 \pm 1.7$ & 0.1288 \\
\hline Walking & $1.0 \pm 1.5$ & $1.0 \pm 1.5$ & $1.0 \pm 1.4$ & $1.3 \pm 1.8$ & $1.0 \pm 1.5$ & $1.0 \pm 1.5$ & 0.1214 \\
\hline Passive range of motion & $1.0 \pm 1.7$ & $1.2 \pm 1.9$ & $1.0 \pm 1.6$ & $1.0 \pm 1.8$ & $0.8 \pm I .4$ & $1.0 \pm 1.7$ & 0.0247 \\
\hline Bed transfer & $0.6 \pm 1.5$ & $0.5 \pm 1.3$ & $0.4 \pm 1.1$ & $1.0 \pm 2.0$ & $0.6 \pm I .4$ & $0.5 \pm 1.4$ & $<0.0001$ \\
\hline Dressing and/or grooming & $0.6 \pm 1.6$ & $0.7 \pm 1.7$ & $0.3 \pm 1.0$ & $1.1 \pm 2.1$ & $0.7 \pm 1.7$ & $0.3 \pm 1.3$ & $<0.0001$ \\
\hline Eating and/or swallowing & $0.4 \pm 1.2$ & $0.4 \pm 1.2$ & $0.4 \pm 1.3$ & $0.3 \pm 1.1$ & $0.3 \pm 1.1$ & $0.4 \pm 1.3$ & 0.3618 \\
\hline Bed mobility & $0.3 \pm 1.2$ & $0.3 \pm 1.1$ & $0.2 \pm 0.9$ & $0.7 \pm 1.8$ & $0.3 \pm 1.1$ & $0.2 \pm 1.0$ & $<0.000$ I \\
\hline Splint or brace assistance & $0.2 \pm 0.9$ & $0.2 \pm 1.0$ & $0.3 \pm 0.9$ & $0.3 \pm 1.1$ & $0.2 \pm 0.9$ & $0.2 \pm 0.8$ & 0.5124 \\
\hline Communication & $0.1 \pm 0.5$ & $0.0 \pm 0.3$ & $0.0 \pm 0.1$ & $0.1 \pm 0.5$ & $0.1 \pm 0.6$ & $0.1 \pm 0.8$ & 0.0382 \\
\hline All other restorative care & $0.2 \pm 0.8$ & $0.1 \pm 0.3$ & $0.2 \pm 0.9$ & $0.2 \pm 0.9$ & $0.3 \pm 0.9$ & $0.3 \pm 1.0$ & $<0.0001$ \\
\hline
\end{tabular}

Notes: Data shown as $\mathrm{n}(\%)$ or mean \pm SD. tUtilization day refers to resident weekly use of the therapy recorded in each assessment document. A day is counted if a therapy or care was provided for at least 15 minutes. ${ }^{\ddagger} p$-values were from multiple comparisons of geographic regions with ANOVA test.

Abbreviations: SD, standard deviation; ANOVA, analysis of variance.

ratio, for-profit facilities, hospital-based facilities, lower deficiency sum score, race/ethnicity, admission from acute care facilities, low VA health care priority, and poor baseline ADL. Significant covariates in the restorative nursing care model include less certified beds, lower resident/nurse ratio, nonprofit facilities, non-hospital-based facilities, admission from non-acute care facilities, and poor baseline ADL (Table 3).

Part 2 Model findings are shown in Table 5. The expected weekly days of rehabilitation therapy and restorative nursing care were 6.4 and 5.9 days among users, respectively, with significant regional variations (North Atlantic: 6.6/6.1; Southeast: 7.2/5.1; Midwest: 5.9/7.3; Continental: 5.8/5.6; and Pacific: 6.2/5.5 days) (Table 4).

Significant covariates in the rehabilitation therapy model were urban facilities, less certified beds, for-profit facilities, hospital-based facilities, married, admitted from acute care facilities, low VA health care priority, less comorbid burden, and higher ADL. Significant covariates in the restorative model included non-profit and hospital-based facilities (Table 5).

\section{Discussion}

The first objective of this study was to determine rehabilitation therapy and restorative nursing care utilization by veterans with stroke in VA-contracted CNHs.

Our results showed that $75.7 \%$ and $30.1 \%$ of the veterans in our study have received rehabilitation therapy and restorative nursing care, respectively, during their $\mathrm{CNH}$ stays. The number of pre-adjusted rehabilitation therapy and restorative nursing care days averaged 6.4 and 5.9 days per week, respectively (Table 2). We found no relevant literature to benchmark our findings. In an early study on physical rehabilitation among elderly residents at skilled nursing facilities in Michigan and Ohio, the rehabilitation therapy prevalence was $79.9 \%$ for the residents. ${ }^{24}$ However, this study differed from ours in that the study residents were older than our veteran cohort and the reported rehabilitation prevalence was for all medical diagnoses, whereas our study focused solely on stroke diagnoses. Regardless, we found that rehabilitation therapy prevalence was high and the users received almost one therapy daily.

The high prevalence of rehabilitation therapy may be associated with two factors: 1) it may demonstrate the actual therapies delivered to veterans by the providers following the treatment plan specified in their per diem contract with VA; 2) alternatively, the high utilization may represent upcodes in therapy minutes by the providers. A recent study reported that nursing homes may upcode their residents' rehabilitation therapy minutes to increase revenue. ${ }^{25}$ According to the report, upcoding is visualized by plotting the frequency of therapy minutes and noting a clustering of high frequencies just above the amounts necessary to place reimbursement in the next higher category. Furthermore, providers have economic incentives to upcode the therapy as rehabilitation minutes documented in the MDS determine the Resource 
Table 3 Results from logistic regression: $(\mathrm{N}=6,206)^{\dagger}$

\begin{tabular}{|c|c|c|c|c|c|c|}
\hline \multirow[t]{2}{*}{ Variables } & \multicolumn{3}{|c|}{ Rehabilitation therapy } & \multicolumn{3}{|c|}{ Restorative nursing care } \\
\hline & Coefficient \pm SE & OR (Cl) & $p$-value & Coefficient \pm SE & OR (Cl) & $p$-value \\
\hline Regions & & & $<0.000$ I & & & $<0.0001$ \\
\hline North Atlantic vs Pacific & $1.29 \pm 0.11$ & $3.65(2.92,4.55)$ & & $-0.13 \pm 0.09$ & $0.88(0.74,1.04)$ & \\
\hline Southeast vs Pacific & $0.84 \pm 0.11$ & $2.31(1.86,2.88)$ & & $-0.67 \pm 0.10$ & $0.51(0.43,0.62)$ & \\
\hline Midwest vs Pacific & $0.17 \pm 0.11$ & $1.18(0.96,1.45)$ & & $-0.29 \pm 0.10$ & $0.75(0.62,0.90)$ & \\
\hline Continental vs Pacific & $0.08 \pm 0.11$ & $1.08(0.88,1.34)$ & & $-0.21 \pm 0.10$ & $0.81(0.67,0.99)$ & \\
\hline North Atlantic vs Continental & $1.21 \pm 0.12$ & $3.37(2.64,4.29)$ & & $0.07 \pm 0.10$ & $1.08(0.88,1.32)$ & \\
\hline Southeast vs Continental & $0.76 \pm 0.12$ & $2.13(1.69,2.69)$ & & $-0.46 \pm 0.11$ & $0.63(0.51,0.78)$ & \\
\hline Midwest vs Continental & $0.09 \pm 0.11$ & $1.09(0.88,1.36)$ & & $-0.08 \pm 0.11$ & $0.92(0.75,1.13)$ & \\
\hline North Atlantic vs Midwest & $1.13 \pm 0.11$ & $3.08(2.47,3.85)$ & & $0.16 \pm 0.09$ & $1.17(0.98,1.40)$ & \\
\hline Southeast vs Midwest & $0.67 \pm 0.11$ & $1.95(1.57,2.44)$ & & $-0.37 \pm 0.10$ & $0.69(0.56,0.84)$ & \\
\hline North Atlantic vs Southeast & $0.46 \pm 0.12$ & $1.58(1.25,2.00)$ & & $0.53 \pm 0.09$ & $1.70(1.42,2.04)$ & \\
\hline \multicolumn{7}{|l|}{ Facility characteristics } \\
\hline Rural vs urban & $-0.15 \pm 0.07$ & $0.86(0.74,0.99)$ & 0.035 & Removed & & \\
\hline Certified beds: per 100 beds & $-0.30 \pm 0.04$ & $0.74(0.69,0.80)$ & $<0.0001$ & $-0.20 \pm 0.04$ & $0.82(0.76,0.88)$ & $<0.0001$ \\
\hline Resident/bed ratio & $0.35 \pm 0.25$ & $1.42(0.87,2.32)$ & 0.17 & $0.40 \pm 0.23$ & $1.50(0.96,2.33)$ & 0.075 \\
\hline Resident/nurse ratio: per 50 points & $-0.11 \pm 0.03$ & $0.9(0.84,0.96)$ & 0.0016 & $-0.12 \pm 0.04$ & $0.89(0.82,0.97)$ & 0.0052 \\
\hline Ownership: reference $=$ non-profit & & & 0.05 & & & $<0.0001$ \\
\hline For-profit & $0.22 \pm 0.11$ & $1.25(1.01,1.54)$ & & $-0.57 \pm 0.08$ & $0.56(0.48,0.67)$ & \\
\hline Local government & $0.05 \pm 0.13$ & $1.05(0.82,1.35)$ & & $-0.30 \pm 0.11$ & $0.74(0.60,0.91)$ & \\
\hline Hospital based: yes vs no & $0.45 \pm 0.21$ & $1.57(1.05,2.35)$ & 0.029 & $-0.95 \pm 0.21$ & $0.39(0.26,0.58)$ & $<0.0001$ \\
\hline Deficiency score: per 70 points & $-0.08 \pm 0.03$ & $0.92(0.87,0.98)$ & 0.01 & Removed & & \\
\hline \multicolumn{7}{|l|}{ Resident characteristics } \\
\hline Age, years: reference $=\geq 80$ & & & 0.065 & Removed & & \\
\hline$\leq 64$ & $-0.19 \pm 0.09$ & $0.83(0.69,0.99)$ & & & & \\
\hline $65-69$ & $0.00 \pm 0.14$ & $1.00(0.76,1.30)$ & & & & \\
\hline $70-74$ & $0.16 \pm 0.12$ & $1.18(0.93,1.50)$ & & & & \\
\hline $75-79$ & $0.01 \pm 0.10$ & $1.01(0.83,1.22)$ & & & & \\
\hline Female vs male & Removed & & & $0.20 \pm 0.15$ & $\mathrm{I} .23(0.9 \mathrm{I}, \mathrm{I} .65)$ & 0.18 \\
\hline $\begin{array}{l}\text { Education: reference = graduate } \\
\text { degree }\end{array}$ & & & 0.10 & Removed & & \\
\hline$<$ High school & $-0.13 \pm 0.18$ & $0.88(0.6 \mathrm{I}, \mathrm{I} .26)$ & & & & \\
\hline High school & $0.0004 \pm 0.18$ & $\mathrm{I} .00(0.7 \mathrm{I}, \mathrm{I} .4 \mathrm{I})$ & & & & \\
\hline Some college & $0.03 \pm 0.18$ & $1.03(0.72,1.47)$ & & & & \\
\hline Bachelor degree & $0.20 \pm 0.21$ & $1.23(0.82,1.85)$ & & & & \\
\hline $\begin{array}{l}\text { Race/ethnicity: reference = all } \\
\text { others }\end{array}$ & & & $<0.0001$ & Removed & & \\
\hline White & $0.4 I \pm 0.15$ & $1.51(1.12,2.02)$ & & & & \\
\hline African-American & $-0.09 \pm 0.17$ & $0.92(0.66,1.27)$ & & & & \\
\hline Marital status: reference $=$ married & Removed & & & & & 0.08 \\
\hline Never married & & & & $0.14 \pm 0.09$ & $1.16(0.96,1.39)$ & \\
\hline Widowed & & & & $-0.04 \pm 0.08$ & $0.96(0.83,1.12)$ & \\
\hline Separated or divorced & & & & $0.17 \pm 0.08$ & $1.19(1.02,1.39)$ & \\
\hline $\begin{array}{l}\text { Admission source: reference }= \\
\text { acute care hospital }\end{array}$ & & & $<0.0001$ & & & $<0.0001$ \\
\hline Non-acute hospital & $-1.10 \pm 0.08$ & $0.33(0.29,0.39)$ & & $0.17 \pm 0.07$ & $1.18(1.02,1.37)$ & \\
\hline Nursing home & $-1.22 \pm 0.10$ & $0.30(0.24,0.36)$ & & $0.50 \pm 0.09$ & $1.65(1.38,1.96)$ & \\
\hline VA priority: high vs other & $-0.21 \pm 0.13$ & $0.81(0.63,1.04)$ & $<0.0001$ & $0.14 \pm 0.11$ & $1.15(0.93,1.42)$ & \\
\hline Comorbidity: numerical & $-0.04 \pm 0.02$ & $0.96(0.92,1.00)$ & 0.056 & Removed & & \\
\hline ADL at baseline: numerical & $0.04 \pm 0.005$ & $1.04(1.03,1.05)$ & $<0.0001$ & $0.03 \pm 0.004$ & $1.03(1.03,1.04)$ & \\
\hline
\end{tabular}

Notes: ${ }^{\dagger}$ Covariates with $p$-value $>0.2$ were removed in the model during the backward selection.

Abbreviations: SE, standard error; OR, odds ratio; Cl, confidence interval; VA, Veterans Affairs; ADL, activities of daily living. 
Table 4 Regional expected probability of therapy utilization ${ }^{\dagger}$ and average days per week of therapy received, among those who did receive therapy ${ }^{\dagger \dagger}$

\begin{tabular}{|c|c|c|c|c|c|c|}
\hline Therapy type & North Atlantic & Southeast & Midwest & Continental & Pacific & All \\
\hline Rehabilitation & 0.88 & 0.83 & 0.66 & 0.66 & 0.70 & 0.76 \\
\hline Restorative & 0.34 & 0.23 & 0.28 & 0.30 & 0.34 & 0.30 \\
\hline \multicolumn{7}{|c|}{ Those receiving therapy } \\
\hline Rehabilitation & 6.57 & 7.24 & 5.93 & 5.75 & 6.24 & 6.44 \\
\hline Restorative care & 6.05 & 5.08 & 7.29 & 5.64 & 5.49 & 5.92 \\
\hline
\end{tabular}

Notes: tThe expected probability of utilization was calculated at the patient level first and then averaged by region using a logistic regression model. ${ }^{\dagger t}$ The expected average weekly utilization was calculated at the patient level first and then averaged by region using a linear regression model.

Utilization Group score calculation, which in turn determines the providers' amount of reimbursement from Medicare. To test this hypothesis of reported rehabilitation minutes upcoding, we examined rehabilitation minutes frequency of our data and observed a similar pattern in minutes upcoding with a previous research report; ${ }^{25}$ however, our finding in minutes upcoding was less pronounced. If upcoding is present, its blunted nature may be due to a removal of incentive when care is paid for by per diem contract.

Our results also showed that the most commonly used rehabilitation therapies were physical therapy and occupational therapy, and the most commonly used restorative nursing techniques included active range of motion, walking, and passive range of motion (Table 2). These specific therapy types and restorative techniques were consistent with clinical guideline-recommended long-term rehabilitation goals of care for stroke survivors: to regain ability in carrying out ADL, reduce the effect of remaining deficits, and live as independently as feasible. ${ }^{1}$ With rehabilitation therapy, physical therapists help stroke patients regain the use of their strokeimpaired limbs and establish physical training programs to retain the newly learned skills. Similarly, occupational therapists help stroke patients acquire skills needed for performing self-directed activities (eg, self-grooming, preparing meals, and housecleaning). With training, registered and licensed practical nurses and/or nursing assistants help patients maintain the functioning achieved in rehabilitation therapy using different restorative nursing techniques such as actively help (passive) or help without physical assistance (active) to move the impaired limbs, perform exercises, or facilitate walking.

Contrary to our expectations, we found that less than onethird of the veterans received restorative nursing care during their $\mathrm{CNH}$ stays. This step down from rehabilitation therapy to restorative nursing care may be because providers lacked financial incentive to provide and/or document the care in the MDS assessment form since restorative nursing care is not as prominent in determining facility reimbursement and quality of care assessment. It may also indicate a mismatch between the amount of staffing needed and the amount of staffing a facility can afford.
The second objective of the study was to assess the regional variations in rehabilitation therapy and restorative nursing care utilization. We hypothesized no significant variations in the utilization outcomes across the five VA regions. Contrary to our hypothesis, we observed a significant variation in rehabilitation therapy and restorative nursing care utilization across the five MyVA regions. Consistently, our results demonstrated that veterans in the North Atlantic and Southeast CNHs were significantly more likely to receive rehabilitation therapies than their counterparts from other regions in terms of observed, adjusted probability and expected utilization. However, veterans in the Southeast facilities were significantly less likely to receive restorative nursing care compared with veterans in other regions before or after risk adjustment. To understand the potential contributing factors for the variation, we found that veterans in North Atlantic and Southeast facilities were significantly more likely to be admitted directly from acute care settings and have poorer average ADL score compared with veterans from other regions.

Our study and findings are important on several fronts: first, the study fills in the gaps by providing rehabilitation therapy and restorative nursing care utilization by all veterans with stroke at the VA-contracted CNHs. Second, our findings will help VA policymakers at different levels to understand the types and intensity (number of weekly days) of rehabilitation therapy and restorative nursing care received by the veterans at the VA-contracted CNHs, as well as the geographic variation of these health services utilizations. Third, our study results will lay the ground work for developing future research in the field, such as quality of care for the veterans and the impact of veterans' rehabilitation and restorative nursing care utilization on the changes of their functional outcomes (i.e., ADL, cognitive function, and depression status).

Our study results were based upon all veterans diagnosed with stroke residing in VA-contracted CNHs over a period of 4 years (2006-2009); nonetheless, facility variation in VA's contract and policy implications should be considered with caution. Since this study is part of a larger study intended to compare the rehabilitation utilization and functional outcomes between VA CLCs and CNHs, we were limited in 
Table 5 Results from linear regression

\begin{tabular}{|c|c|c|c|c|}
\hline \multirow[t]{2}{*}{ Variables } & \multicolumn{2}{|c|}{ Rehabilitation therapy $(\mathrm{N}=4,695)$} & \multicolumn{2}{|c|}{ Restorative nursing care $(\mathrm{N}=1,867)$} \\
\hline & Coefficient \pm SE & p-value & Coefficient \pm SE & p-value \\
\hline Regions & & $<0.0001$ & & 0.0002 \\
\hline North Atlantic vs Pacific & $0.54 \pm 0.19$ & & $0.34 \pm 0.41$ & \\
\hline Southeast vs Pacific & $0.83 \pm 0.19$ & & $-0.94 \pm 0.48$ & \\
\hline Midwest vs Pacific & $-0.30 \pm 0.21$ & & $1.37 \pm 0.46$ & \\
\hline Continental vs Pacific & $-0.28 \pm 0.21$ & & $0.22 \pm 0.46$ & \\
\hline North Atlantic vs Continental & $0.82 \pm 0.20$ & & $0.12 \pm 0.45$ & \\
\hline Southeast vs Continental & $1.11 \pm 0.21$ & & $-1.16 \pm 0.52$ & \\
\hline Midwest vs Continental & $-0.02 \pm 0.22$ & & $1.15 \pm 0.50$ & \\
\hline North Atlantic vs Midwest & $0.84 \pm 0.19$ & & $-1.03 \pm 0.45$ & \\
\hline Southeast vs Midwest & $1.12 \pm 0.20$ & & $-2.3 I \pm 0.50$ & \\
\hline North Atlantic vs Southeast & $-0.29 \pm 0.17$ & & $1.28 \pm 0.46$ & \\
\hline \multicolumn{5}{|l|}{ Facility characteristics } \\
\hline Rural vs urban & $-0.54 \pm 0.13$ & $<0.0001$ & Removed & \\
\hline Certified beds: per 100 beds & $-0.49 \pm 0.09$ & $<0.0001$ & Removed & \\
\hline Resident/bed ratio & Removed & & Removed & \\
\hline Resident/nurse ratio: per 50 points & Removed & & Removed & \\
\hline Ownership: reference $=$ non-profit & & $<0.0001$ & & $<0.0001$ \\
\hline For-profit & $0.65 \pm 0.17$ & & $-1.00 \pm 0.4$ & \\
\hline Local government & $-1.62 \pm 0.23$ & & $-2.38 \pm 0.46$ & \\
\hline Hospital based: yes vs no & $0.74 \pm 0.37$ & 0.043 & $2.92 \pm 1.12$ & 0.0091 \\
\hline Deficiency score: per 70 points & $-0.11 \pm 0.06$ & 0.08 & $-0.26 \pm 0.15$ & 0.073 \\
\hline \multicolumn{5}{|l|}{ Resident characteristics } \\
\hline Age, years: reference $=\geq 80$ & & 0.069 & Removed & \\
\hline$\leq 64$ & $-0.37 \pm 0.18$ & & & \\
\hline $65-69$ & $-0.20 \pm 0.25$ & & & \\
\hline $70-74$ & $0.24 \pm 0.21$ & & & \\
\hline $75-79$ & $0.03 \pm 0.17$ & & & \\
\hline Female vs male & Removed & 0.47 & Removed & \\
\hline Education: reference $=$ graduate degree & & 0.35 & Removed & \\
\hline \multicolumn{5}{|l|}{$<$ High school } \\
\hline \multicolumn{5}{|l|}{ High school } \\
\hline \multicolumn{5}{|l|}{ Some college } \\
\hline \multicolumn{5}{|l|}{ Bachelor degree } \\
\hline Race/ethnicity: reference $=$ all others & & 0.17 & & 0.052 \\
\hline White & $0.20 \pm 0.32$ & & $-0.25 \pm 0.70$ & \\
\hline African-American & $0.01 \pm 0.35$ & & $0.84 \pm 0.77$ & \\
\hline Marital status: reference $=$ married & & $<0.0001$ & Removed & \\
\hline Never married & $-0.97 \pm 0.20$ & & & \\
\hline Widowed & $-0.33 \pm 0.15$ & & & \\
\hline Separated/divorced & $-0.48 \pm 0.17$ & & & \\
\hline Admission source: reference $=$ acute care hospital & & $<0.0001$ & Removed & \\
\hline Non-acute hospital & $-1.68 \pm 0.16$ & & & \\
\hline Nursing home & $-2.56 \pm 0.20$ & & & \\
\hline VA priority: high vs other & $-0.43 \pm 0.21$ & $<0.0001$ & Removed & \\
\hline Comorbidity: numerical & $-0.09 \pm 0.04$ & 0.027 & Removed & \\
\hline ADL at baseline: numerical & $0.06 \pm 0.01$ & $<0.0001$ & Removed & \\
\hline
\end{tabular}

Notes: "Removed" indicates the variable was eliminated during the backward selection procedure.

Abbreviations: SE, standard error; VA, Veterans Affairs; ADL, activities of daily living.

including some of the variables commonly used in $\mathrm{CNH}$ studies (eg, the Resource Utilization Group score). We included a number of facility and veteran characteristic variables by linking the MDS data with the VA and non-VA inpatient and outpatient utilization databases.

\section{Conclusion}

The majority of veterans with stroke received rehabilitation therapy, and about one-third had restorative nursing care during their $\mathrm{CNH}$ stays. We found significant variations in the observed probability and estimated rehabilitation utilization 
across the five MyVA regions. Our findings provide needed information about veterans' post-stroke rehabilitation therapy at $\mathrm{CNHs}$ and insights regarding the care variations across the five newly defined MyVA regions.

\section{Acknowledgments}

This study was supported through the US Department of Veterans Affairs Health Services Research and Development Service (VA HSR\&D Grant \#: IIR 11-330). The opinions and contents of this paper are those of the authors and they do not represent the views of the US Department of Veterans Affairs or the United States Government. Support for VA/ CMS data is provided by the VA Information Resource Center (Project \#: SDR 02-237 and 98-004).

The abstract of this paper was presented at the AcademyHealth Annual Research Meeting on June 27, 2016, in Boston, MA, USA, as a poster presentation with interim findings. ${ }^{26,27}$

\section{Disclosure}

The authors report no conflicts of interest in this work.

\section{References}

1. Bates B, Choi JY, Duncan PW, et al. Veterans Affairs/Department of Defense clinical practice guideline for the management of adult stroke rehabilitation care: executive summary. Stroke. 2005;36(9):2049-2056.

2. Wright SM, Petersen LA, Lamkin RP, Daley J. Increasing use of medicare services by veterans with acute myocardial infarction. Med Care. 1999;37(6):529-537.

3. Department of Veterans Affairs (VA). Change 2 to Appendix E, Memorandum No. 11-17: Community Nursing Home, Placement, and Follow-up. Gainesville, FL: North Florida/South Georgia Veterans Health System; 2005.

4. United States General Accountability Office (GAO). VA Long-term Care: Oversight of Nursing Home Program Impeded by Data Gaps (GAO-05-65). Washington, DC: United States General Accountability Office (GAO); 2005.

5. Department of Veterans Affairs Office of Public Affairs Media Relations. Fact Sheet: VA Long-term Care. Washington, DC: Department of Veterans Affairs Office of Public Affairs Media Relations; 2005.

6. United States General Accountability Office (GAO). VA Long-term Care: Oversight of Community Nursing Homes Needs Strengthening (GAO-01-768). Washington, DC: United States General Accountability Office (GAO); 2001.

7. Johnson CE, Weech-Maldonado R, Huanguang Jia, Reker D, Buchanan R, Laberge A. Characteristics of community nursing homes serving per diem veterans, 1999 to 2002. Med Care Res Rev. 2007;64:673-690.

8. Jia H, Pei Q, Sullivan CT, et al. Poststroke rehabilitation and restorative care utilization: a comparison between VA community living centers and VA-contracted community nursing homes. Med Care. 2016;54:235-242.
9. Cifu DX, Stewart DG. Factors affecting functional outcome after stroke: a critical review of rehabilitation interventions. Arch Phys Med Rehabil. 1999;80:S35-S39.

10. Evans RL, Connis RT, Hendricks RD, Haselkorn JK. Multidisciplinary rehabilitation versus medical care: a meta-analysis. Soc Sci Med. 1995;40:1699-1706.

11. Dobkin BH. Clinical practice. Rehabilitation after stroke. N Engl J Med. 2005;352:1677-1684.

12. Centers for Medicare and Medicaid Services (CMS). Long-term Care Minimum Data Set (MDS). 2014. Available from: http://www.Cms.Gov/ research-statistics-data-and-systems/files-for-order/identifiabledatafiles/ longtermcareminimumdatasetmds.Html. Accessed December 12, 2016.

13. Morris JN, Moore T, Jones R, et al. Report No. 500-59-0062/T.O. No. 4. Washington, DC: Centers for Medicare and Medicaid Services; 2002.

14. Jia H, Zheng Y, Reker DM, et al. Multiple system utilization and mortality for veterans with stroke. Stroke. 2007;38(2):355-360.

15. United States Department of Veterans Affairs. VA announces single regional framework under MyVA initiative. Available at: http://www. blogs.va.gov/VAntage/16786/. Accessed December 12, 2016.

16. Ripley B. FY2006 Geographic Access to Veterans Health Administration. Gainesville, FL: VA Planning System Support Group and Health Analysis and Information Group; 2008.

17. Jia H, Cowper DC, Tang Y, Litt E, Wilson L. Postacute stroke rehabilitation utilization: are there differences between rural-urban patients and taxonomies? J Rural Health. 2012;28(3):242-247.

18. Centers for Medicare and Medicaid Services (CMS). Nursing Home Data Compendium 2013 Ed. 2014. Available from: http://www.Cms. Gov/medicare/provider-enrollment-and-certification/certificationandcomplianc/downloads/nursinghomedatacompendium_508.Pdf. Accessed December 12, 2016.

19. Jia H, Zheng YE, Cowper DC, et al. How veterans use stroke services in the VA and beyond. Fed Practit. 2006;23(21-24):41.

20. Jia H, Damush TM, Qin H, et al. The impact of poststroke depression on healthcare use by veterans with acute stroke. Stroke. 2006;37(11): 2796-2801.

21. Morris JN, Fries BE, Morris SA. Scaling ADLs within the MDS. J Gerontol A Biol Sci Med Sci. 1999;54(11):M546-M553.

22. Buchanan JL, Andres PL, Haley SM, Paddock SM, Zaslavsky AM. An assessment tool translation study. Health Care Financ Rev. 2003;24(3):45-60.

23. D'Hoore W, Sicotte C, Tilquin C. Risk adjustment in outcome assessment: the Charlson comorbidity index. Methods Inf Med. 1993;32(5):382-387.

24. Wodchis WP. Physical rehabilitation following medicare prospective payment for skilled nursing facilities. Health Serv Res. 2004;39(5):1299-1318.

25. Bowblis JR, Brunt CS. Medicare skilled nursing facility reimbursement and upcoding. Health Econ. 2014;23(7):821-840.

26. Jia H, Hale-Gallardo J. Regional Variation in Post-Stroke Rehabilitation Care Among Veteran Residents in Community Nursing Homes. Poster abstract presented at: AcademyHealth Annual Research Meeting, June 27, 2016, Boston, MA, USA. Available at: https://academyhealth.confex. com/academyhealth/2016arm/meetingapp.cgi/Paper/8329. Accessed January 31, 2017.

27. Jia C, Pei Q, Sullivan CT, et al. Regional Variation in Post-Stroke Rehabilitation Care Among Veteran Residents in Community Nursing Homes. Abstract presented at: AcademyHealth Annual Research Meeting, June 27, 2016, Boston, MA, USA. Available at: https://www. researchgate.net/publication/304817374_Regional_Variation_in_PostStroke_Rehabilitation_Care_Among_Veteran_Residents_in_Community_Nursing_Homes. Accessed January 31, 2017. 


\section{Publish your work in this journal}

The Journal of Multidisciplinary Healthcare is an international, peerreviewed open-access journal that aims to represent and publish research in healthcare areas delivered by practitioners of different disciplines. This includes studies and reviews conducted by multidisciplinary teams as well as research which evaluates the results or conduct of such teams or health care processes in general. The journal covers a very wide range of areas and welcomes submissions from practitioners at all levels, from all over the world. The manuscript management system is completely online and includes a very quick and fair peer-review system. Visit http://www.dovepress.com/ testimonials.php to read real quotes from published authors.

Submit your manuscript here: https://www.dovepress.com/journal-of-multidisciplinary-healthcare-journal 